\title{
MicroRNA-187 inhibits tumor growth and metastasis via targeting of IGF-1R in hepatocellular carcinoma
}

\author{
XINQIANG HAN ${ }^{1,2^{*}}$, XUEMIN WANG ${ }^{3 *}$, BAOLEI ZHAO ${ }^{4}$, GANG CHEN $^{1}$, YUGUO SHENG $^{1}$, \\ WENMING WANG ${ }^{1}$ and MUJIAN TENG ${ }^{2}$
}

\author{
${ }^{1}$ Department of Interventional Medicine and Vascular Surgery, The Affiliated Hospital of Binzhou Medical \\ University, Binzhou, Shandong 256603; ${ }^{2}$ Department of Hepatobiliary Surgery, Qianfoshan Hospital Affiliated \\ to Shandong University, Jinan, Shandong 250014; Departments of ${ }^{3}$ Gastroenterology and ${ }^{4}$ Hepatobiliary \\ Surgery, The Affiliated Hospital of Binzhou Medical University, Binzhou, Shandong 256603, P.R. China
}

Received June 30, 2016; Accepted June 8, 2017

DOI: $10.3892 / \mathrm{mmr} .2017 .6788$

\begin{abstract}
Hepatocellular carcinoma (HCC) is the primary and most frequently occurring type of malignant liver cancer, accounting for $70-85 \%$ of total liver cancer cases worldwide. It has previously been demonstrated that the aberrant expression of microRNAs (miR) contributes to carcinogenesis and progression of various human malignancies, including HCC. However, mechanisms underlying the differential expression and specific roles of miR-187 in $\mathrm{HCC}$ remain to be elucidated, particularly regarding how the modulation of malignant phenotypes in HCC cells occurs. The present study demonstrated that miR-187 was significantly downregulated in HCC tissues and cell lines. Restoration of miR-187 expression inhibited cell proliferation, migration and invasion in HCC. Furthermore, insulin-like growth factor 1 receptor (IGF-1R) was demonstrated to act as a direct target gene of miR-187 in HCC. IGF-1R knockdown mimicked the effects of miR-187 overexpression in $\mathrm{HCC}$, resulting in a significant inhibition of cell proliferation, migration and invasion. The results of the present study demonstrated that miR-187 acted as a tumor suppressor in HCC progression via direct targeting of IGF-1R. miR-187 may therefore exhibit the potential to act as a novel and therapeutic target for HCC treatment in the future.
\end{abstract}

Correspondence to: Professor Xuemin Wang, Department of Gastroenterology, The Affiliated Hospital of Binzhou Medical University, 661 Huanghe 2nd Road, Binzhou, Shandong 256603, P.R. China

E-mail: wangxuemin116@163.com

Professor Mujian Teng, Department of Hepatobiliary Surgery, Qianfoshan Hospital Affiliated to Shandong University, 16766 Jingshi Road, Jinan, Shandong 250014, P.R. China

E-mail: mujiant66@163.com

${ }^{*}$ Contributed equally

Key words: microRNA-187, hepatocellular carcinoma, IGF-1R, growth, metastasis

\section{Introduction}

Hepatocellular carcinoma (HCC) is the most common malignant primary liver cancer and accounts for $70-85 \%$ of the total liver cancer cases worldwide (1). It is the fifth most commonly diagnosed cancer and the third leading cause of cancer-related death worldwide, with an estimated over 500,000 new cases and 600,000 deaths due to HCC per year (2-4). Development of HCC involves a variety of etiological factors, including infection with hepatitis B virus (HBV) and hepatitis $\mathrm{C}$ virus (HCV), chronic alcohol consumption, intake of dietary aflatoxin B1, arsenic exposure, obesity, and non-alcoholic fatty liver disease (5-7). On the basis of tumor differentiation, HCC could be divided into four histological grades, including well differentiated (G1), moderately differentiated (G2), poorly differentiated (G3), and undifferentiated (G4) types (8). Currently, surgical resection and liver transplantation are the major curative therapeutic strategies for patients with HCC (9). Although great progress has been achieved in the diagnostic techniques and treatments of HCC, the prognosis remains unsatisfactory with an overall 5-year survival rate of only 5\% (10). The poor prognosis of HCC cases is a results of recurrence even after surgery, early invasion into blood vessels, intra-hepatic metastases and extra-hepatic metastases (11). Therefore, it is necessary to fully understand the molecular mechanisms underlying the progression of HCC and explore novel efficacious therapeutic targets for this disease.

microRNAs (miRNAs) are a type of endogenous, highly conserved and non-coding short RNAs with approximately 19-25 nucleotides in length (12). By pairing to complementary binding sites within the 3 'untranslated regions (3'UTRs) of their target genes, miRNAs suppressed their protein translation or induced degradation of target mRNAs (13). As regulators of gene expression, miRNAs play a critical role in a wide range of important biological process, such as cell proliferation, differentiation, apoptosis, cell cycle, metabolism, invasion, metastasis, angiogenesis, immunity, and development (14-16). Abundant reports have demonstrated that the aberrant expression of miRNAs contributes to carcinogenesis and progression of human malignancies, also including HCC (17-19). Indeed, miRNAs are frequently located in genomic breakpoint regions 
and can act as tumor suppressors or oncogenes in human cancers, depending on the roles of their target genes (20). For example, miR-548a-5p is upregulated in HCC and targets a tumor suppressor, $\mathrm{Tg} 737$, to promote cell proliferation and repress apoptosis (21); whereas miR-186 is downregulated in $\mathrm{HCC}$ and inhibits cell proliferation, migration and invasion via targeting Yes-associated protein 1 (22). Therefore, miRNAs could be promising therapeutic targets for HCC patients.

In this study, we measured miR-187 expression in HCC tissues and cell lines, investigated its functions on HCC cells proliferation, migration and invasion, and explored its underlying molecular mechanisms. Our results demonstrated that miR-187 was downregulated in HCC and acted as a tumor suppressor through directly targeting insulin-like growth factor 1 receptor (IGF-1R).

\section{Materials and methods}

Ethic statement and tissues samples. The present study was approved by the Ethics Committee at Qianfoshan Hospital Affiliated to Shandong University (Jinan, China). All HCC patients in this study had not been treated with chemotherapy or radiotherapy prior to surgery section. Experimental procedure were performed following to the Declaration of Helsinki and the federal regulation on human research in the People's Republic of China. Sixteen HCC tissues and adjacent non-tumor tissues were collected at the Department of Hepatobiliary Surgery, Qianfoshan Hospital Affiliated to Shandong University (Jinan, China) between June 2013 and October 2014. All tissues samples were immediately frozen in liquid nitrogen and stored at $-80^{\circ} \mathrm{C}$.

Cell culture. HCC cell lines, HepG2, SMMC-7721, Hep3B, and Huh7 were obtained from the Cell Bank of Type Culture Collection of Chinese Academy of Sciences (Shanghai, China), and cultured in Dulbecco's modified Eagle's medium (DMEM) supplemented with $10 \%$ fetal bovine serum (FBS) (Gibco, Grand Island, NY, USA). The immortalized normal liver epithelial cell line, THLE-3, was purchased from ATCC (Manassas, VA, USA), and grown under the conditions provided by the manufacturer. All cells were cultured at $37^{\circ} \mathrm{C}$ in a humidified incubator with $5 \% \mathrm{CO}_{2}$.

Transient transfection. miR-187 mimics and miRNA mimics negative control (NC) were obtained from GenePharma (Shanghai, China). The duplexes of siRNA targeting IGF-1R (IGF-1R siRNA) and the negative control (NC siRNA) were purchased from RIBOBIO (Guangzhou, China). Cells were transfected with these oligonucleotide by Lipofectamine 2000 (Invitrogen Life Technologies, Carlsbad, CA, USA), in accordance with the manufacturer's instructions.

RNA extraction and quantitative real-time reverse transcription-PCR ( $q R T-P C R)$. Expressions levels of miR-187 and IGF-1R mRNA were measured by using qRT-PCR. Total RNA was extracted from tissues or cells with TRIzol reagent (Invitrogen, Carlsbad, CA, USA). Reverse transcription was done with M-MLV Reverse Transcriptase (Promega, Madison, WI, USA), followed by real-time PCR with SYBR Premix Ex Taq $^{\text {TM }}$ (Takara, Dalian, China). Relative miR-187 or IGF-1R
mRNA expression were calculated as $2^{-\Delta \Delta C t}$ and were normalized to U6 or GAPDH, respectively.

3-(4,5-dimethylthiazolyl-2-yl)-2-5 diphenyl tetrazolium bromide (MTT) assay. HCC cells (3,000 cells/well) were seeded in 96 -well plates. At $24 \mathrm{~h}$ following transient transfection, cells were cultured at $37^{\circ} \mathrm{C}$ in a humidified incubator with $5 \% \mathrm{CO}_{2}$ for $1,2,3$, and 4 days, respectively. At each time-point, MTT assay (Sigma, St. Louis, MO, USA) was performed. In briefly, $20 \mu \mathrm{l}$ MTT solution $(5 \mathrm{mg} / \mathrm{ml})$ was placed in each well and cultured at $37^{\circ} \mathrm{C}$ for additional $4 \mathrm{~h}$. Subsequently, the culture medium was removed and replaced with $150 \mu \mathrm{l}$ DMSO (Sigma). Cells were incubated at room temperature for $10 \mathrm{~min}$, and the plates were shaken for $10 \mathrm{~min}$ with an Eppendorf Mixmate (Eppendorf, GRE) for fully dissolution of MTT crystals. The optical density (OD) at $490 \mathrm{~nm}$ was detected using a microplate reader (Bio-Rad, Richmond, CA, USA).

Migration and invasion assay. Cell migration and invasion were measured using a Transwell chamber model $(8-\mu \mathrm{m}$ pore size; Millipore, Billerica, MA, USA). Transfected cells were harvested $48 \mathrm{~h}$ post-transfection and suspended at a concentration of $3 \times 10^{5}$ cells $/ \mathrm{ml}$. For migration assay, $150 \mu \mathrm{l}$ of the suspension was added into the upper chambers. For invasion assay, $150 \mu \mathrm{l}$ of the suspension was placed into the upper chambers pre-coated with Matrigel (BD Biosciences, Franklin Lakes, NJ, USA). Cells were then incubated at $37^{\circ} \mathrm{C}$ in a humidified incubator with $5 \% \mathrm{CO}_{2}$ for $48 \mathrm{~h}$. Cells remaining in the upper chambers were removed carefully with cotton wool. Migrated or invaded cells through the membranes were fixed in $10 \%$ formalin and stained with $0.5 \%$ crystal violet. Five visual fields (x200) were randomly photographed from each membrane by using an inverted microscope. All experiments were performed in triplicate.

miR-187 target predictions. The putative targets of miR-187 were analyzed by using miRNA target prediction programs: miRDB (http://mirdb.org/cgi-bin/), and TargetScan (http://www.targetscan.org/).

Luciferase reporter assay. Luciferase reporter plasmids, pGL3-IGF-1R-3'UTR Wt and pGL3-IGF-1R-3'UTR Mut, were constructed by GenePharma. For luciferase reporter assay, HEK293T cells were seeded into 24-well plates and grown to $60-70 \%$ confluence. Cells were co-transfected with pGL3-IGF-1R-3'UTR Wt or pGL3-IGF-1R-3'UTR Mut, and miR-187 mimics or NC using Lipofectamine ${ }^{\circledR} 2000$. Transfeted cells were incubated at $37^{\circ} \mathrm{C}$ in a humidified incubator with $5 \%$ $\mathrm{CO}_{2}$ for $48 \mathrm{~h}$ and harvested for luciferase activities measurement with Dual-luciferase reporter assay system (Promega). Firefly luciferase activities were normalized to its corresponding Renilla luciferase activities.

Protein extraction and western blot. After transfection $72 \mathrm{~h}$, cells were collected for total protein extraction using radio-immunoprecipitation assay (RIPA) buffer supplemented with protease inhibitors (Roche, Shanghai, China). BCA Protein Assay kit (Santa Cruz Biotechnology, Santa Cruz, CA, USA) was used to measure total protein concentration. Equivalent proteins were separated on a $10 \%$ 

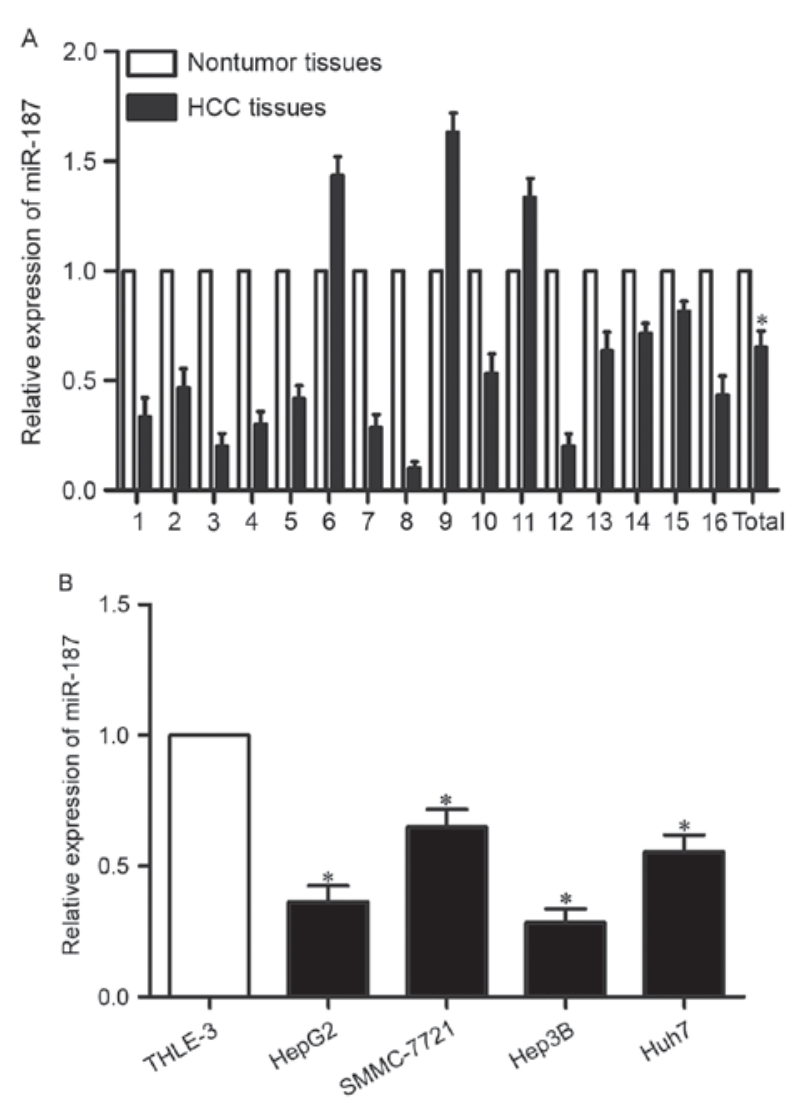

Figure 1. Analysis of miR-187 expression in HCC tissues and cell lines. (A) Expression of miR-187 in HCC tissues and their adjacent nontumor tissues were determined by using qRT-PCR. U6 was used as the control for miR-187. (B) The relative expression of miR-187 was detected in four HCC cell lines (HepG2, SMMC-7721, Hep3B, Huh7) and a immortalized normal liver epithelial cell line (THLE-3). ${ }^{*} \mathrm{P}<0.05$ compared with their respective controls.

SDS-polyacrylamide gel (PAGE) and transferred to polyvinylidenefluoride (PVDF) membranes (Millipore, Boston, MA, USA). In order to block non-specific binding, the membranes were then incubated with $5 \%$ skim milk in Tris-buffered saline and $0.1 \%$ Tween-20 (TBST) at room temperature for $1 \mathrm{~h}$. Subsequently, the membranes were probed with mouse anti-human IGF-1R monoclonal primary antibody (1:1,000 dilution, ab985) and mouse anti-human GADPH monoclonal primary antibody (1:1,000 dilution, ab127428) (both from Abcam, Tokyo, Japan), at $4^{\circ} \mathrm{C}$ overnight. After washing with TBST, goat anti-mouse horseradish peroxidase conjugated secondary antibody (1:5,000 dilution; Abcam) were added for $2 \mathrm{~h}$ at room temperature. Finally, the signal was visualized using enhanced chemiluminescence (Millipore, Billerica, WI, USA).

Statistical analysis. All data were presented as mean \pm SD., and compared using SPSS 19.0 (SPSS Inc., Chicago, IL, USA). Double-tailed $\mathrm{P}<0.05$ was considered to be statistically significant.

\section{Results}

Expression of miR-187 was downregulated in HCC tissues and cell lines. To investigate miR-187 expression in HCC, we
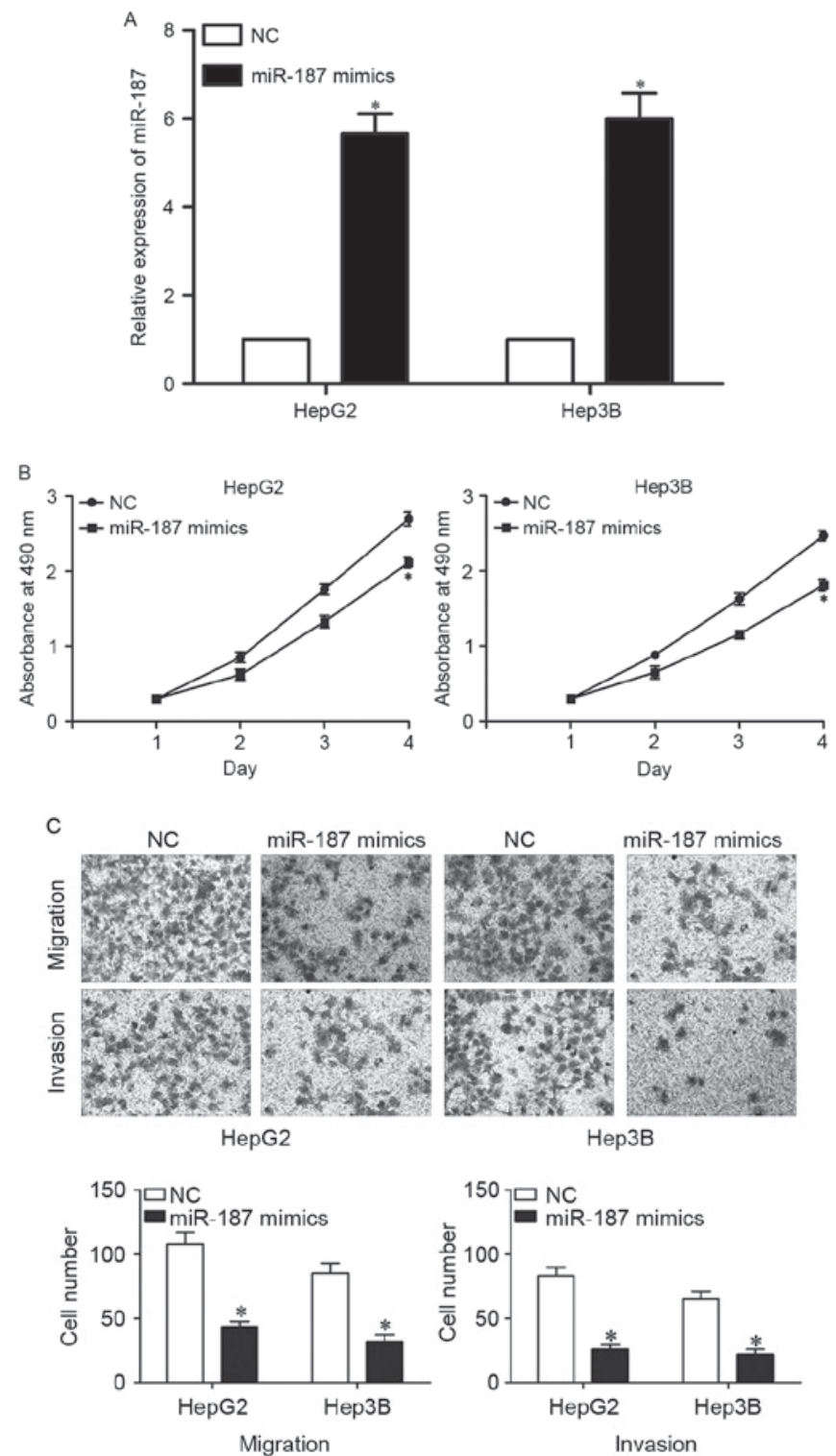

Figure 2. miR-187 inhibited proliferation, migration and invasion in HCC cells. (A) HepG2 and Hep3B cells were transfected with miR-187 mimics or NC. Expression of miR-187 was detected by using qRT-PCR $48 \mathrm{~h}$ post-transfection. (B) Effect of miR-187 on cell proliferation was measured by MTT assay. (C) Ectopic of miR-187 expression decreased cell migration and invasion capacities in $\mathrm{HCC}$. ${ }^{*} \mathrm{P}<0.05$ compared with their respective controls.

compared its expression levels between HCC tissues and their adjacent nontumor tissues. Results of qRT-PCR showed that expression of miR-187 was lower in HCC tissues than those in adjacent nontumor tissues (Fig. 1A, P<0.05). Furthermore, the miR-187 expression was also measured in HCC cell lines as well as immortalized normal liver epithelial cells THLE-3. The results showed that miR-187 was downregulated in all HCC cell lines compared with THLE-3 (Fig. 1B, P<0.05). HepG2 and Hep3B cell lines, expressed relatively lower expression of miR-187, were chosen as representatives for further functional experiments.

miR-187 overexpression inhibited cell proliferation, migration and invasion of HCC. To investigate the biological functions of miR-187 in HCC, miR-187 mimics was used to increase its expression in HepG2 and Hep3B cells (Fig. 2A, P<0.05). MTT 

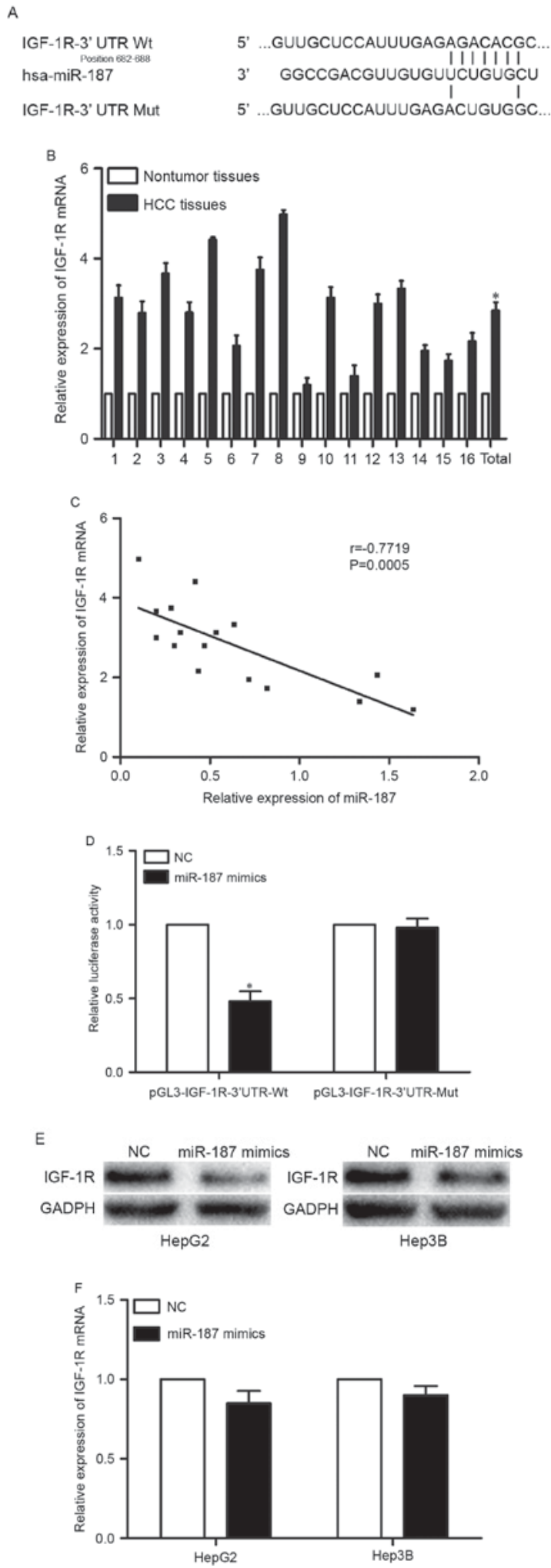

Figure 3. miR-187 directly targeted IGF-1R in HCC. (A) Schematic representation of IGF-1R 3'UTR was showing the putative miR-187 target sites. (B) qRT-PCR analysis showed that IGF-1R mRNA was significantly up-regulated in HCC tissues compared with their adjacent nontumor tissues. GADPH was used as the internal control for IGF-1R mRNA expression. (C) Spearman's correlation analysis found an inverse correlation between miR-187 and IGF-1R mRNA expression in clinical HCC tissues. (D) Relative luciferase activities were measured after luciferase reporter plasmids were co-transfected with miR-187 mimics or NC into HEK293T cells. (E) Western blot was performed to measure endogenous IGF-1R protein expression in HepG2 and Hep3B cells transfected with miR-187 mimics or NC. (F) qRT-PCR analysis of IGF-1R mRNA expression in HepG2 and Hep3B cells transfected with miR-187 mimics or NC. ${ }^{*} \mathrm{P}<0.05$ compared with their respective controls. assay showed that upregulation of miR-187 significantly inhibited the HepG2 and Hep3B cells proliferation (Fig. 2B, P<0.05). The migration and invasion abilities of HepG2 and Hep3B cells were also dramatically reduced by miR-187 overexpression (Fig. 2C, $\mathrm{P}<0.05$ ). These results suggested that miR-187 may act as a tumor suppressor in HCC.

$I G F-1 R$ was a target gene of $m i R-187$. It is generally believed that miRNAs play critical roles in biological process through negatively regulation of their target genes via directly binding to the 3'UTR. To understand the mechanism underlying the tumor suppressive roles of miR-187 in HCC, we searched for its downstream target genes. Bioinformatic analysis revealed that IGF-1R may be a direct target gene of miR-187 (Fig. 3A). First, we detected IGF-1R mRNA expression in HCC tissues and their adjacent nontumor tissues by using qRT-PCR. Interestingly, IGF-1R mRNA was significantly upregulated in HCC tissues in comparison with adjacent nontumor tissues (Fig. 3B, P<0.05). Moreover, Spearman's correlation analysis found an inverse correlation between miR-187 and IGF-1R mRNA expression in HCC tissues ( $r=-0.7719$, $\mathrm{P}=0.0005$, Fig. 3C).

Tofurther confirm thishypothesis, the pGL3-IGF-1R-3'UTR Wt or pGL3-IGF-1R-3'UTR Mut were transfected into HEK293T cells together with miR-187 mimics or NC. The results showed that the relative luciferase activities of pGL3-IGF-1R-3'UTR Wt was obviously decreased in miR-187 mimics group as compared with NC group (Fig. 3D, $\mathrm{P}<0.05$ ). However, the luciferase activities of pGL3-IGF-1R-3'UTR Mut was unaffected by co-transfection of miR-187 mimics.

The downregulation of IGF-1R protein in HepG2 and Hep3B after transfection with miR-187 mimics further confirmed that IGF-1R was a direct target gene of miR-187 (Fig. 3E, P<0.05). Moreover, upregulation of miR-187 had no regulation effect on IGF-1R mRNA expression, indicating miR-187 regulated IGF-1R expression at post-transcriptional level (Fig. 3F, P>0.05). These results demonstrated that IGF-1R was a direct target of miR-187.

IGF-1R knockdown inhibited cell proliferation, migration and invasion of HCC. To determine whether IGF-1R was a functional target of miR-187 in HCC, HepG2 and Hep3B cells were injected with IGF-1R siRNA or NC siRNA. Western blot analysis showed that IGF-1R was reduced both in HepG2 and Hep3B cells following to transfection with IGF-1R siRNA (Fig. 4A, P<0.05). Functionally, IGF-1R knockdown could simulate the effects of miR-187 overexpression on $\mathrm{HCC}$, resulting in a significant inhibition of cell proliferation (Fig. 4B, P<0.05), migration and invasion (Fig. 4C, P<0.05). These results provided further evidences that IGF-1R was a functional target of miR-187 in HCC.

\section{Discussion}

The dysregulation of miR-187 occurs frequently in many human cancers. miR-187 expression was observed to be downregulated in both renal cell carcinoma tumor tissue and plasma. Reduced miR-187 was closely correlated with higher tumor grade and stage. Moreover, renal cell carcinoma patients with low miR-187 level have poor prognosis compared with patients 

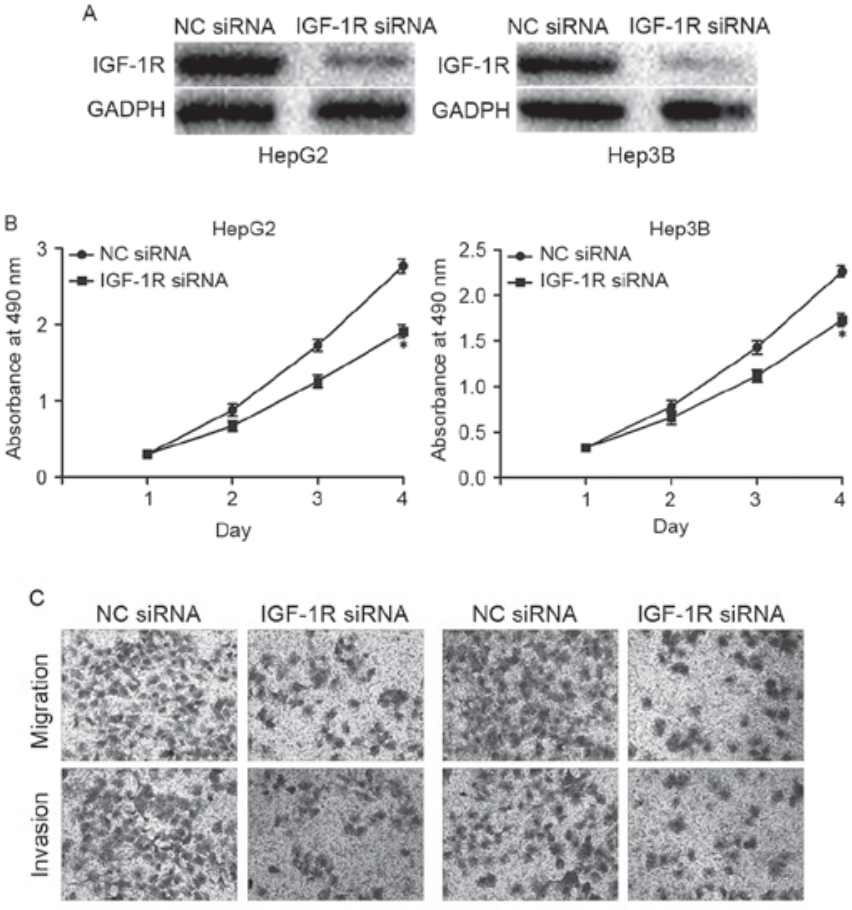

HepG2
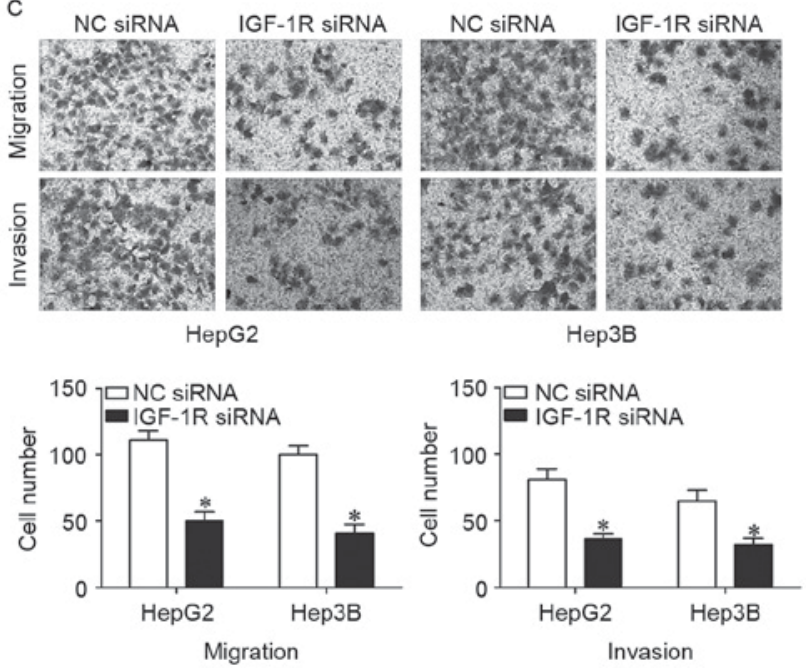

Figure 4. IGF-1R knockdown inhibited proliferation, migration and invasion in HCC cells. (A) Western blot analysis of IGF-1R protein expression in HepG2 and Hep3B cells transfected with IGF-1R siRNA or NC siRNA. (B) Effect of IGF-1R underexpression on HepG2 and Hep3B cells proliferation was measured by MTT assay. (C) IGF-1R knockdown inhibited HepG2 and Hep3B cells migration and invasion abilities. ${ }^{*} \mathrm{P}<0.05$ compared with their respective controls.

with high miR-187 expression (23). In colorectal cancer, expression level of miR-187 was lower in tumor tissues and cell lines. Kaplan-Meier analysis revealed that reduced miR-187 expression was associated with shorter overall survival and relapse-free survival of patients with colorectal cancer (24). Consistent with these results, downregulation of miR-187 was also found in prostate cancer (25) and lung cancer $(26,27)$. However, others have reported that miR-187 was upregulated in certain tumor types. In ovarian cancer, expression of miR-187 was higher in tumor tissues, and its expression was obviously correlated with better overall survival and recurrence-free survival. Further, multivariate analysis indicated that miR-187 served as an independent prognostic factor for patients with ovarian cancer (28). These conflicting findings suggest that miR-187 has a tumor and tissue-specific expression pattern. In our current study, miR-187 was found to be significantly downregulated in HCC tissues and cell lines, which provides additional information about the expression level of miR-187 in human cancer. Several lines of evidence implicate the miR-187 in cancer development. Zhao et al demonstrated that ectopic of miR-187 expression suppressed cell growth and motility in vitro, and decreased cell growth in vivo trough directly targeting B7-H3 (23). In non-small cell lung cancer, upregulation of miR-187 inhibited cell proliferation, colony formation, migration, invasion, and induced apoptosis via suppression of BCL-6 expression (27). Wang et al found that miR-187 repressed cell proliferation, migration, invasion, and promoted cell apoptosis of colorectal cancer by negatively regulation of CD276 (24). Study by Lynam-Lennon et al reported that miR-187 overexpression improved sensitivity of esophageal adenocarcinoma cells to X-ray radiation and cisplatin (29). These studies provided evidences to suggest that miR-187 functions as a tumor suppressor; however, others have reported that miR-187 may play an oncogenic role in other human cancers. For example, restoration of miR-187 promoted ovarian cancer cells proliferation, migration and epithelial-to-mesenchymal transition via blockade of Disabled homolog-2 (28). These conflicting observations also indicate that functions of miR-187 has a tumor and tissue-specific dependence. In this study, for the first time, we demonstrated that enforced miR-187 expression in HCC cells inhibited cell proliferation, migration and invasion. These studies suggested that miR-187 play significant roles in tumor development.

Furthermore, our data also verified that IGF-1R was a direct functional target of miR-187 in HCC. There are several lines of evidence to demonstrate this. First, bioinformatic analysis showed that 3'UTR of IGF-1R contained potential binding sites of miR-187. Second, IGF-1R mRNA was upregulated in clinical HCC tissues and inversed correlated with miR-187 expression. Third, upregulation of miR-187 suppressed luciferase activities of pGL3-IGF-1R-3'UTR Wt, and this suppressive effect could be abolished by mutation of the miR-187 seed binding sites, suggesting miR-187 could directly targeted the 3'UTR of IGF-1R. Fourth, miR-187 overexpression decreased IGF-1R protein expression, but not IGF-1R mRNA expression of HCC, indicating miR-187 regulated IGF-1R expression at posttranscriptional level. Finally, the suppressive effect of IGF-1R knockdown on HCC cells were similar with those induced by miR-187 overexpression. These results demonstrated that the tumor suppressive roles of miR-187 was partly mediated by downregulation of IGF-1R.

IGF-1R, a member of the insulin receptor family of receptor tyrosine kinases, has been reported to be upregulated in multiple types of cancer, such as HCC (30), prostate cancer (31), lung cancer (32), gastric cancer (33), bladder cancer (34) and so on.

Significant amount of studies demonstrated that IGF-1R is capable of mediating both IGF-I and IGF-II signaling and regulates a great deal of cellular processes including cell cycle, migration, metabolism, survival, proliferation, and differentiation (31,35-37). Increasing studies suggested that IGF-1R knockdown could inhibit cell growth $(38,39)$, invasion $(40)$, and improve cell apoptosis $(38,40)$ and chemo-sensitivity (39). These findings provide sufficient evidence that IGF-IR plays important roles in hepatocarcinogenesis and HCC progression, and therefore may be a promising therapeutic target.

In conclusion, we demonstrated that miR-187 was downregulated in HCC tissues and cell lines. Overexpression of miR-187 inhibited HCC growth and metastasis through directly targeting IGF-1R. These findings provide insights into the pathogenesis and development of HCC, which could 
be used to explore novel therapeutic strategies for HCC treatments.

\section{References}

1. Perz JF, Armstrong GL, Farrington LA, Hutin YJ and Bell BP: The contributions of hepatitis $B$ virus and hepatitis $C$ virus infections to cirrhosis and primary liver cancer worldwide. J Hepatol 45: 529-538, 2006.

2. Siegel RL, Miller KD and Jemal A: Cancer statistics, 2015. CA Cancer J Clin 65: 5-29, 2015.

3. Schwartz M, Roayaie S and Konstadoulakis M: Strategies for the management of hepatocellular carcinoma. Nat Clin Pract Oncol 4: 424-432, 2007.

4. Poon RT and Fan ST: Hepatectomy for hepatocellular carcinoma: Patient selection and postoperative outcome. Liver Transpl 10 (2 Suppl 1): S39-S45, 2004.

5. Yu MC and Yuan JM: Environmental factors and risk for hepatocellular carcinoma. Gastroenterology 127 (5 Spuul 1): S72-S78, 2004.

6. El-Serag HB and Rudolph KL: Hepatocellular carcinoma: Epidemiology and molecular carcinogenesis. Gastroenterology 132: 2557-2576, 2007.

7. Park KU, Seo YS, Lee YH, Park J, Hwang I, Kang KJ, Nam J, Kim SW and Kim JY: Altered microRNA expression profile in hepatitis B virus-related hepatocellular carcinoma. Gene 573: 278-284, 2015.

8. Han DH, Choi GH, Kim KS, Choi JS, Park YN, Kim SU, Park JY, Ahn SH and Han KH: Prognostic significance of the worst grade in hepatocellular carcinoma with heterogeneous histologic grades of differentiation. J Gastroenterol Hepatol 28: 1384-1390, 2013.

9. Bosch FX, Ribes J, Diaz M and Cléries R: Primary liver cancer: Worldwide incidence and trends. Gastroenterology 127 (5 Suppl 1): S5-S16, 2004.

10. Zhang Y, Guo X, Xiong L, Kong X, Xu Y, Liu C, Zou L, Li Z, Zhao J and Lin N: MicroRNA-101 suppresses SOX9-dependent tumorigenicity and promotes favorable prognosis of human hepatocellular carcinoma. FEBS Lett 586: 4362-4370, 2012.

11. Harlan LC, Parsons HM, Wiggins CL, Stevens JL and Patt YZ: Treatment of hepatocellular carcinoma in the community: Disparities in standard therapy. Liver Cancer 4: 70-83, 2015.

12. Croce $\mathrm{CM}$ and Calin GA: miRNAs, cancer, and stem cell division. Cell 122: 6-7, 2005.

13. Papaconstantinou I, Karakatsanis A, Gazouli M, Polymeneas G and Voros D: The role of microRNAs in liver cancer. Eur J Gastroenterol Hepatol 24: 223-228, 2012.

14. Ambros V: The functions of animal microRNAs. Nature 431: 350-355, 2004.

15. Bartel DP: MicroRNAs: Genomics, biogenesis, mechanism, and function. Cell 116: 281-297, 2004.

16. Rottiers V, Najafi-Shoushtari SH, Kristo F, Gurumurthy S, Zhong L, Li Y, Cohen DE, Gerszten RE, Bardeesy N, Mostoslavsky R and Näär AM: MicroRNAs in metabolism and metabolic diseases. Cold Spring Harb Symp Quant Biol 76: 225-233, 2011

17. Lujambio A and Lowe SW: The microcosmos of cancer. Nature 482: 347-355, 2012.

18. Dou C, Wang Y, Li C, Liu Z, Jia Y, Li Q, Yang W, Yao Y, Liu Q and Tu K: MicroRNA-212 suppresses tumor growth of human hepatocellular carcinoma by targeting FOXA1. Oncotarget 6 : 13216-13228, 2015.

19. Wang X, Chen J, Li F, Lin Y, Zhang X, Lv Z and Jiang J: miR-214 inhibits cell growth in hepatocellular carcinoma through suppression of $\beta$-catenin. Biochem Biophys Res Commun 428: $525-531,2012$

20. Garzon R, Calin GA and Croce CM: MicroRNAs in cancer. Annu Rev Med 60: 167-179, 2009.

21. Zhao G, Wang T, Huang QK, Pu M, Sun W, Zhang ZC, Ling R and Tao KS: MicroRNA-548a-5p promotes proliferation and inhibits apoptosis in hepatocellular carcinoma cells by targeting Tg737. World J Gastroenterol 22: 5364-5373, 2016.

22. Ruan T, He X, Yu J and Hang Z: MicroRNA-186 targets Yes-associated protein 1 to inhibit Hippo signaling and tumorigenesis in hepatocellular carcinoma. Oncol Lett 11: 2941-2945, 2016.
23. Zhao J, Lei T, Xu C, Li H, Ma W, Yang Y, Fan S and Liu Y: MicroRNA-187, down-regulated in clear cell renal cell carcinoma and associated with lower survival, inhibits cell growth and migration though targeting B7-H3. Biochem Biophys Res Commun 438: 439-444, 2013.

24. Wang ZS, Zhong M, Bian YH, Mu YF, Qin SL, Yu MH and Qin J: MicroRNA-187 inhibits tumor growth and invasion by directly targeting CD276 in colorectal cancer. Oncotarget 7: 44266-44276, 2016.

25. Casanova-Salas I, Masiá E, Armiñán A, Calatrava A, Mancarella C, Rubio-Briones J, Scotlandi K, Vicent MJ and López-Guerrero JA: miR-187 targets the androgen-regulated gene ALDH1A3 in prostate cancer. PLoS One 10: e0125576, 2015.

26. Mirzadeh Azad F, Naeli P, Malakootian M, Baradaran A, Tavallaei M, Ghanei M and Mowla SJ: Two lung development-related microRNAs, miR-134 and miR-187, are differentially expressed in lung tumors. Gene 577: 221-226, 2016.

27. Sun C, Li S, Yang C, Xi Y, Wang L, Zhang F and Li D: MicroRNA-187-3p mitigates non-small cell lung cancer (NSCLC) development through down-regulation of BCL6. Biochem Biophys Res Commun 471: 82-88, 2016.

28. Chao A, Lin CY, Lee YS, Tsai CL, Wei PC, Hsueh S, Wu TI, Tsai CN, Wang CJ, Chao AS, et al: Regulation of ovarian cancer progression by microRNA-187 through targeting disabled homolog-2. Oncogene 31: 764-775, 2012.

29. Lynam-Lennon N, Bibby BA, Mongan AM, Marignol L, Paxton CN, Geiersbach K, Bronner MP, O'Sullivan J, Reynolds J and Maher SG: Low miR-187 expression promotes resistance to chemoradiation therapy in vitro and correlates with treatment failure in patients with esophageal adenocarcinoma. Mol Med 22: 2016.

30. E C, Li J, Shao D, Zhang D, Pan Y, Chen L and Zhang X: The insulin-like growth factor-I receptor inhibitor picropodophyllin-induced selective apoptosis of hepatocellular carcinoma cell through a caspase-dependent mitochondrial pathway. Oncol Res 21: 103-110, 2013

31. Ma Y, Cheng Q, Ren Z, Xu L, Zhao Y, Sun J, Hu S and Xiao W: Induction of IGF-1R expression by EGR-1 facilitates the growth of prostate cancer cells. Cancer Lett 317: 150-156, 2012.

32. Wei YH, Tang HX, Liao YD, Fu SL, Xu LQ, Chen G, Zhang C, Ju S, Liu ZG, You LK, et al: Effects of insulin-like growth factor 1 receptor and its inhibitor AG1024 on the progress of lung cancer. J Huazhong Univ Sci Technolog Med Sci 35: 834-841, 2015.

33. Gryko M, Kisluk J, Cepowicz D, Zińczuk J, Kamocki Z, Guzińska-Ustymowicz K, Pryczynicz A, Czyżewska J, Kemona A and Kedra B: Expression of insulin-like growth factor receptor type 1 correlate with lymphatic metastases in human gastric cancer. Pol J Pathol 65: 135-140, 2014.

34. Xie QX, Lin XC, Zhang MF, Han CX and Guo YH: Expression of IGF-I and IGF-IR in bladder cancer. Ai Zheng 23: 707-709, 2004 (In Chinese).

35. Singh RK, Gaikwad SM, Jinager A, Chaudhury S, Maheshwari A and Ray P: IGF-1R inhibition potentiates cytotoxic effects of chemotherapeutic agents in early stages of chemoresistant ovarian cancer cells. Cancer Lett 354: 254-262, 2014.

36. Chen HX and Sharon E: IGF-1R as an anti-cancer target-trials and tribulations. Chin J Cancer 32: 242-252, 2013.

37. Singh I, Amin H, Rah B and Goswami A: Targeting EGFR and IGF 1R: A promising combination therapy for metastatic cancer. Front Biosci (Schol Ed) 5: 231-246, 2013.

38. Yue L, Wang Y, Wang H, Gao H, Liang J, Sui A, Xiang J, Zhou F, $\mathrm{Xu} \mathrm{C}$, Zhao W, et al: Inhibition of hepatocellular carcinoma cell growth by an anti-insulin-like growth factor-I receptor monoclonal antibody. Oncol Rep 28: 1453-1460, 2012.

39. Zhang YW, Yan DL, Wang W, Zhao HW, Lu X, Wu JZ and Zhou JR: Knockdown of insulin-like growth factor I receptor inhibits the growth and enhances chemo-sensitivity of liver cancer cells. Curr Cancer Drug Targets 12: 74-84, 2012.

40. Yao WF, Liu JW, Sheng GL and Huang DS: Blockade of IGF-IR exerts anticancer effects in hepatocellular carcinoma. Mol Med Rep 4: 719-722, 2011. 